\title{
Article \\ Reference Values of Thromboelastometry Parameters in Healthy Term Neonates Using NATEM in Cord Blood Samples
}

\author{
Alma Sulaj ${ }^{1,+}$, Marina Tsaousi ${ }^{1,+}$, Eleni Karapati ${ }^{1}$, Abraham Pouliakis ${ }^{2}$ (D) Zoi Iliodromiti $^{1}$ (D), \\ Theodora Boutsikou ${ }^{1}$, Serena Valsami ${ }^{3}$, Nicoletta Iacovidou ${ }^{1}$, Marianna Politou ${ }^{3}$ and Rozeta Sokou ${ }^{1,4, *}$ (D)
}

1 Neonatal Department, Aretaieio Hospital, School of Medicine, National and Kapodistrian University of Athens, 11528 Athens, Greece; alma_sulaj@hotmail.com (A.S.); marina_11@windowslive.com (M.T.); helenak5@hotmail.com (E.K.); ziliodromiti@yahoo.gr (Z.I.); theobtsk@gmail.com (T.B.); niciac58@gmail.com (N.I.)

2 2nd Department of Pathology, University General Hospital Attikon, School of Medicine, National and Kapodistrian University of Athens, 12462 Athens, Greece; apou1967@gmail.com

3 Hematology Laboratory Blood Bank, Aretaieio Hospital, School of Medicine, National and Kapodistrian University of Athens, 11528 Athens, Greece; serenavalsami@yahoo.com (S.V.); mariannapolitou@gmail.com (M.P.)

4 Neonatal Intensive Care Unit, “Agios Panteleimon” General Hospital of Nikaia, 18454 Piraeus, Greece

* Correspondence: sokourozeta@yahoo.gr; Tel.: +30-21-3207-7346 or +30-21-3207-7000

+ These authors contributed equally to this work.

check for updates

Citation: Sulaj, A.; Tsaousi, M.;

Karapati, E.; Pouliakis, A.;

Iliodromiti, Z.; Boutsikou, T.; Valsami, S.; Iacovidou, N.; Politou, M.; Sokou,

R. Reference Values of

Thromboelastometry Parameters in

Healthy Term Neonates Using NATEM in Cord Blood Samples. Children 2022, 9, 47. https://doi.org/ $10.3390 /$ children 9010047

Received: 1 December 2021

Accepted: 29 December 2021

Published: 2 January 2022

Publisher's Note: MDPI stays neutral with regard to jurisdictional claims in published maps and institutional affiliations.

Copyright: (C) 2022 by the authors. Licensee MDPI, Basel, Switzerland. This article is an open access article distributed under the terms and conditions of the Creative Commons Attribution (CC BY) license (https:// creativecommons.org/licenses/by/ $4.0 /)$.

\begin{abstract}
Background: ROTEM assay has gained increasing acceptance as a method for rapid and specific coagulation pathway assessment. However, its use in the neonatal population remains limited since reference ranges have not yet been established. Aims: (1) to determine reference ranges for healthy term neonates of ROTEM parameters using non-activated assay (NATEM) in cord blood samples; (2) to assess whether delivery mode, gender, gestational age, birth weight and blood group (ABO and Rhesus) of the neonate, coagulation disorder and anticoagulant medication of the mother have an impact on NATEM parameters. Methods: NATEM assay was conducted in cord blood samples of 189 term neonates without any medical history. Results: Reference ranges (2.5th and 97.5th percentiles) are established for clotting time (CT), clot formation time (CFT), $\alpha$-angle, clot amplitude at 5, 10 and $20 \mathrm{~min}(\mathrm{~A} 5, \mathrm{~A} 10, \mathrm{~A} 20)$, maximum clot firmness (MCF), lysis index at 30 and $60 \mathrm{~min}$ (LI30, LI60, \%) and maximum clot elasticity (MCE). Reference ranges for NATEM are CT 182-499 s, CFT 63-176 s, $\alpha$-angle 58-78 , A5 28-52 mm, A10 37-61 mm, A20 42-66 mm, MCF 43-67 mm, LI30 97-100\%, LI60 87-98\% and MCE 75-203. Male neonates appear to be more hypocoagulable than females. Conclusions: We demonstrate reference ranges for healthy term neonates in NATEM assay that could be used as a reference group for future studies of neonates with an underlying pathology.
\end{abstract}

Keywords: thromboelastometry; NATEM; neonates; coagulation; cord blood; reference ranges

\section{Introduction}

Hemostasis in the neonatal period is an evolving process that starts in the intrauterine life and continues to undergo changes until adulthood. This age-related maturation is described by the term "developmental hemostasis", first described by Maureen Andrews in the 1980's and includes quantitative and qualitative differences in hemostatic factors [1-5]. In the neonate, the concentration and the activity of both pro-coagulant factors (II, VII, IX, $\mathrm{X}, \mathrm{XI}, \mathrm{XII}$ ), and anti-coagulant proteins (protein-S and -C) are below adult values. As to the platelets, although their number is within normal adult values, they appear hyporeactive. The increased concentration and the large multimers of von Willebrand factor (VWF), the higher hematocrit and the large nucleated red cells in neonates counterbalanced this hyporeactivity. The fibrinolytic system is immature, with reduced plasmin activity and low levels of plasminogen inhibitor. Despite these differences, healthy neonates have a hemostatic balance, without bleeding or thrombotic tendency [6-8]. 
Conventional coagulation tests used in clinical practice, include prothrombin time (PT), activated partial thromboplastin time (aPTT), international normalized ratio (INR), PLT counts, and fibrinogen. These tests are performed in plasma and they do not reflect the clot dynamic, the platelet function and the fibrinolytic capacity. Therefore, they are not representative of the in vivo hemostatic procedure and this renders their prognostic value of detecting bleeding diathesis of limited value $[9,10]$. Viscoelastic whole-blood analyses include Rotational thromboelastometry $\left(\right.$ ROTEM $^{\circledR}$, Tem Innovations GmbH, München, Germany) and thromboelastography (TEG) system overcome these obstacles. They provide a graphical curve that represents the in-vivo interaction between platelets, coagulation factors, fibrinogen/fibrin, endothelium and overall the formation, stabilization and lysis of the clot. Hence, they do not only detect coagulopathies but they also identify the type of coagulopathy and could thus constitute a useful tool for diagnosis and treatment [11,12]. The first results are readily available within $30 \mathrm{~min}$, offering a prompt bedside evaluation tool for the patient. Thromboelastometry has been studied in adults and children, especially in cardiac surgery, transplantation, trauma, extracorporeal membrane oxygenation patients and obstetrics [13-16]. As far as the neonates are concerned, available data are scarce. Their clinical use is not widespread, due to the lack of reference ranges for this age group. The majority of the existing studies focuses on specific medical conditions such as sepsis, intraventricular hemorrhage (IVH), and hypoxic ischemic encephalopathy treated with therapeutic hypothermia [17-24].

The primary aim of our study was to determine reference ranges for term neonates without any medical history of ROTEM parameters using non-activated assay (NATEM) in cord blood samples, which can be used in future studies. Secondarily, to assess whether delivery mode, gestational age (GA), birth weight (BW), sex and blood group (ABO and Rhesus) of the neonate, coagulation disorder and anticoagulant medication of the mother have an impact on NATEM variables.

\section{Materials and Methods}

This is a longitudinal cohort study. Term neonates without any medical history with gestational age (GA) $\geq 37$ weeks and appropriate birth weight (BW) for GA born at Magginio Maternity Clinic, Aretaieio Hospital, National and Kapodistrian University of Athens, from March 2021 up to November 2021 comprised the study population. The study was in accordance with all the relevant national regulations, and institutional policies and was authorised by the Institutional Review Board of Aretaieio Hospital, National and Kapodistrian University of Athens (Project identification code: 310/26-03-2021). Parental consent after a short briefing was acquired for all neonates included in the study. Data regarding GA, BW, gender, mode of delivery, Apgar score, blood group (ABO and Rhesus) of the neonates and $\mathrm{pH}$ of the umbilical cord were recorded. Data about maternal coagulopathy (such as MTHFR homozygosity, factor V Leiden heterozygosity, homocysteine homozygosity etc.) and use of anticoagulant medication were also documented. Neonates born by emergency cesarean section (CS), with a personal or family history of bleeding disorders, with a chromosomal abnormality or many dysmorphic features, sepsis, perinatal asphyxia, perinatal stress (defined criteria have been previously described [21]), gestational diabetes, with jaundice of the first day of life; small for gestational age (SGA), intrauterine growth restriction (IUGR), large for gestation age (LGA) and finally neonates admitted in neonatal intensive care unit (NICU) were excluded from the study. All neonates were followed up until their discharge. Data regarding recruitment of our study are presented in the flowchart (Figure 1). 


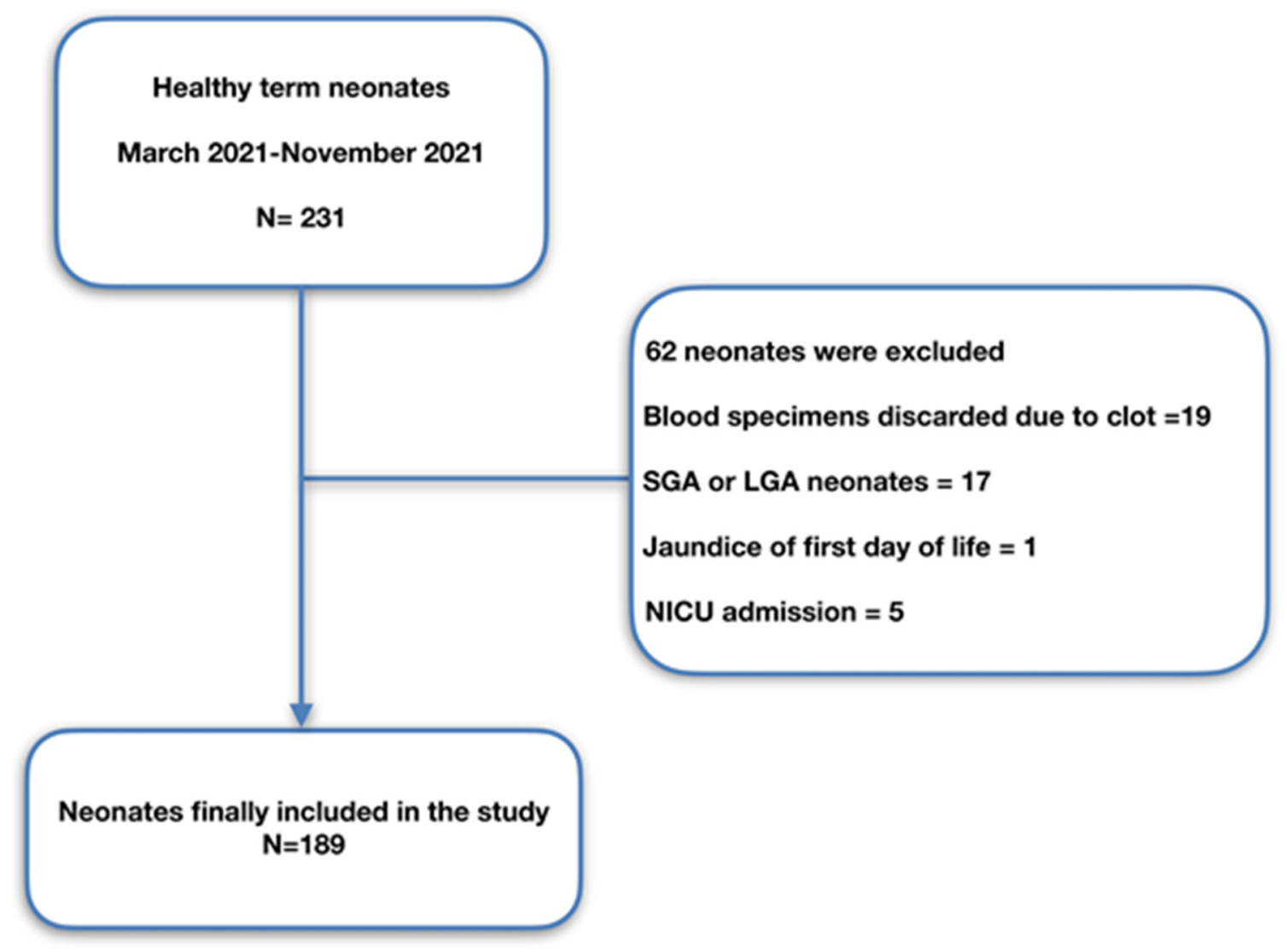

Figure 1. Study population flowchart. SGA, small for gestational age; LGA, large for gestation age; NICU, neonatal intensive care unit.

Cord blood samples were collected from the umbilical cord immediately after clamping using $21 \mathrm{G}$ needle and were then transferred into $3.5 \mathrm{~mL}$ 9NC Coagulation sodium citrate $3.2 \%$ containing VACUETTE ${ }^{\circledR}$ TUBE. Blood samples with fibrin clots were discarded. Whole blood $(300 \mu \mathrm{L})$ was analyzed on the ROTEM ${ }^{\circledR}$ delta analyzer (Tem Innovations $\mathrm{GmbH}$, Munich, Germany) using the NATEM assay. Immediately after collection, the sample was gently inverted five times to resuspend any sediment. It was then incubated for $2-5 \mathrm{~min}$ at $37^{\circ} \mathrm{C}$ and was tested within 30-60 min. The ROTEM test was performed using the respective automated pipette programs according to the manufacturer's guidelines. Clot formation was induced by adding $20 \mu \mathrm{L}$ of $0.2 \mathrm{M}$ calcium chloride solution (starTEM ${ }^{\circledR} 20$ reagent, Tem Innovations $\mathrm{GmbH}$, Munich, Germany). The reagent was added to the cup and then was adequately mixed with $300 \mu \mathrm{L}$ of whole blood anticoagulated with $0.109 \mathrm{~mol} / \mathrm{L}$ trisodium citrate (9:1, v/v blood anticoagulant, Greiner Bio-One $\mathrm{GmbH}$, Kremsmünster, Austria). The assay ran for at least $60 \mathrm{~min}$ after clot lysis at $30 \mathrm{~min}$. The following NATEM variables were recorded: clotting time (CT, seconds), the time passed from the start of measurement until the formation of a clot $2 \mathrm{~mm}$ in amplitude; clot formation time (CFT, seconds), the time between $2 \mathrm{~mm}$ and $20 \mathrm{~mm}$ of clot amplitude clot amplitude at 5, 10 and 20 min after CT (A5, A10, A20); $\alpha$-angle $\left(a^{\circ}\right)$, the angle between the central line ( $x$-axis) and the tangent of the clotting curve at the amplitude point of $2 \mathrm{~mm}$, reflecting the clot kinetics and measured in degrees; maximum clot firmness (MCF, mm), the widest amplitude of main body of trace; lysis index at 30 and $60 \mathrm{~min}$ (LI30, LI60, \%), the percentage of remaining clot stability proportionate to the MCF following the 60-min observation period after $\mathrm{CT}$ indicating the speed of fibrinolysis and maximum clot elasticity $(\mathrm{MCE}=100 \times \mathrm{MCF} /(100-\mathrm{MCF}))$. 


\section{Statistical Analysis}

Statistical analysis was performed within the environment of SAS for Windows version 9.4 platform (SAS Institute Inc., Cary, NC, USA). Descriptive values were expressed using the median value and the relevant quartiles, i.e., Quartile 1 (Q1) to Quartile 3 (Q3) range. Comparisons among the groups for qualitative parameters were performed by the chi-square test (if the number of observations were less than 5 in more than $25 \%$ of the contingency table then the Fisher exact test was used). For continuous variables normality was not always possible to be ensured (as tested via the Kolmogorov-Smirnov test), therefore, non-parametric tests were applied; specifically we applied the Mann Whitney U test when comparing two groups and the Kruskal-Wallis test when comparing more than two groups. The significance level (i.e., threshold for the $p$-value) was set $<0.05$; moreover all statistical tests were two sided.

Calculation of reference values was performed using the value ranges and using non-parametric methods, as these: (i) are simpler to perform and (ii) do not require any assumption on data distributions. For the reference ranges, the 2.5 and 97.5 percentiles are reported, after controlling for outliers for each NATEM

\section{Results}

One hundred and eighty-nine (189) term neonates without any medical history with median gestational age 39 weeks (Q1-Q3 = 39-40 weeks) were the study subjects. Forty-five (45) neonates out of them (23.8\%) had GA between 37 and 38 weeks, $134(70.9 \%)$ had GA between 39 and 40 weeks, and 10 had GA 41 weeks (5.3\%). The median birth weight was $3330 \mathrm{~g}$ (Q1-Q3: 3140-3530) and 45.5\% were females. Baseline characteristics of the study population are demonstrated in Table 1.

Table 1. Baseline characteristics of the study population.

\begin{tabular}{|c|c|c|c|}
\hline & Characteristic & $n$ & Value * \\
\hline \multirow{6}{*}{ Newborns' data } & $\begin{array}{c}\text { GA (weeks) Median } \\
\text { (Q1-Q3) }\end{array}$ & 189 & $39(38-40)$ \\
\hline & $\begin{array}{c}\text { BW (g) Median } \\
\text { (Q1-Q3) }\end{array}$ & 189 & $3330(3140-3530)$ \\
\hline & Gender (females) & 189 & $86(45.5 \%)$ \\
\hline & Apgar score $1 \mathrm{~min}$ & 189 & $9(9-9)$ \\
\hline & Apgar score $5 \mathrm{~min}$ & 189 & $10(10-10)$ \\
\hline & pH (umbilical cord) & 185 & $7.36(7.33-7.38)$ \\
\hline \multirow[t]{2}{*}{$\begin{array}{c}\text { Newborns' laboratory } \\
\text { data }\end{array}$} & Blood group & 183 & $\begin{array}{c}\mathrm{A}(62 / 33.88 \%) \\
\mathrm{B}(35 / 19.13 \%) \\
\mathrm{AB}(8 / 4.37 \%) \\
\mathrm{O}(78 / 42.62 \%)\end{array}$ \\
\hline & Rhesus & 183 & $\begin{array}{c}\text { Positive }(166 / 90.7 \%) \\
\text { Negative }(17 / 9.3 \%)\end{array}$ \\
\hline \multirow{2}{*}{ Maternal data } & $\begin{array}{l}\text { Thrombophilic } \\
\text { history }\end{array}$ & 189 & $11(5.82 \%)$ \\
\hline & $\begin{array}{l}\text { Anticoagulation } \\
\text { treatment }\end{array}$ & 189 & 36 (19.05\%) \\
\hline $\begin{array}{l}\text { Pregnancy and } \\
\text { delivery }\end{array}$ & Delivery mode & 189 & $\begin{array}{c}\text { CS } 116(61.38 \%) \\
\text { VD } 61(32.28 \%) \\
\text { FD } 12(6.35 \%)\end{array}$ \\
\hline
\end{tabular}

Abbreviations: CS, cesarean section; VD, vaginal delivery; FD, forceps delivery; * Measure is expressed as median and $\mathrm{Q} 1-\mathrm{Q} 3$ range, or as frequency and percentage. 
All parameters of NATEM assay are depicted as median values and reference ranges (2.5th and 97.5th percentiles) in Table 2.

Table 2. Reference ranges of NATEM parameters $(N=189)$.

\begin{tabular}{cccc}
\hline Parameter & Median (Q1-Q3) & 2.5 Pctl & 97.5 Pctl \\
\hline CT & $322(250-391)$ & 182 & 499 \\
\hline A5 & $41(36-45.5)$ & 28 & 52 \\
\hline A10 & $51(47-55)$ & 37 & 61 \\
\hline A20 & $57(53-61)$ & 42 & 66 \\
\hline CFT & $97(80-127)$ & 63 & 176 \\
\hline MCF & $58(54-61)$ & 43 & 67 \\
\hline$\alpha$-angle & $71(65-74)$ & 58 & 78 \\
\hline LI30 & $100(99-100)$ & 97 & 98 \\
\hline LI60 & $93(91-95)$ & 87 & 203 \\
\hline MCE & $136.5(118-158.5)$ & 75 & 100 \\
\hline
\end{tabular}

Abbreviations: CT, clotting time (seconds); CFT, clot formation time (seconds); A5, A10, A20, clot amplitude at 5 , 10 and $20 \mathrm{~min},(\mathrm{~mm})$; MCF, maximal clot firmness (mm); LI30, LI60, lysis index at 30 and $60 \mathrm{~min}(\%)$; $\alpha$-angle, alpha angle $\left({ }^{\circ}\right)$; MCE, maximum clot elasticity; NATEM, non-activated rotational thromboelastometry. N: Number of cases, Q1: first quartile, Q3: third quartile.

Statistical analyses showed that GA had a positive, yet weak correlation with LI30 and LI60 ( $\mathrm{r}=+0.193, p=0.008, \mathrm{r}=+0.191, p=0.009$ respectively), while no correlation was found between BW and NATEM parameters $(p>0.05)$. Male neonates appear to have a more hypocoagulable profile compared to females, expressed by the prolonged CT $(p=0.01)$ and lower A20 ( $p=0.03), \operatorname{MCF}(p=0.03), \operatorname{MCE}(p=0.03)$ (Table 3).

Table 3. NATEM parameters and gender of neonates.

\begin{tabular}{cccc}
\hline \multirow{2}{*}{ Parameter } & \multicolumn{2}{c}{ Gender } & \multirow{2}{*}{$p$-Value } \\
\cline { 2 - 4 } & $\begin{array}{c}\text { Males }(\boldsymbol{n}=\mathbf{1 0 3}) \\
\text { Median }(\mathbf{Q 1 - Q 3})\end{array}$ & $\begin{array}{c}\text { Females }(\boldsymbol{n}=\mathbf{8 6}) \\
\text { Median }(\mathbf{Q 1}-\mathbf{Q 3})\end{array}$ & 0.016 \\
\hline CT & $333(280-413)$ & $299.5(245-370)$ & 0.105 \\
\hline A5 & $40(35-45)$ & $42(38-46)$ & 0.079 \\
\hline A10 & $50(46-55)$ & $52(49-55)$ & 0.035 \\
\hline A20 & $56(52-60)$ & $58(55-61)$ & 0.071 \\
\hline CFT & $103(82-137)$ & $92.5(78-121)$ & 0.032 \\
\hline MCF & $57(53-61)$ & $59(56-61)$ & 0.094 \\
\hline$\alpha$-angle & $70(64-74)$ & $71(67-74)$ & 0.952 \\
\hline LI30 & $100(99-100)$ & $100(99-100)$ & 0.915 \\
\hline LI60 & $93(90-95)$ & $93(91-95)$ & 0.032 \\
\hline MCE & $132.5(114-157)$ & $146(127-159)$ & \\
\hline
\end{tabular}

Abbreviations: CT, clotting time (seconds); CFT, clot formation time (seconds); A5, A10, A20, clot amplitude at 5 , 10 and $20 \mathrm{~min},(\mathrm{~mm})$; MCF, maximal clot firmness (mm); LI30, LI60, lysis index at 30 and $60 \mathrm{~min}(\%)$; $\alpha$-angle, alpha angle $\left({ }^{\circ}\right)$; MCE, maximum clot elasticity; NATEM, non-activated rotational thromboelastometry; N: Number of cases, Q1: first quartile, Q3: third quartile.

Delivery mode had no impact on the NATEM parameters for all comparisons (CS, VD, FD, $p>0.05)$ (Table 4). 
Table 4. NATEM parameters and delivery mode.

\begin{tabular}{ccccc}
\hline Parameter & $\begin{array}{c}\text { VD }(n=61) \\
\text { Median } \\
\text { (Q1-Q3) }\end{array}$ & $\begin{array}{c}\text { CS }(n=116) \\
\text { Median } \\
(\mathbf{Q 1 - Q 3})\end{array}$ & $\begin{array}{c}\text { FD }(n=12) \\
\text { Median } \\
(\mathbf{Q 1 - Q 3})\end{array}$ & $p$-Value \\
\hline CT & $322(232-377)$ & $272.5(321-401.5)$ & $283.5(236-378)$ & 0.429 \\
\hline A5 & $42(37.5-46.5)$ & $36(40.5-45)$ & $42.5(35.5-44)$ & 0.389 \\
\hline A10 & $52(47-56)$ & $46.5(50-54)$ & $53(47.5-54)$ & 0.428 \\
\hline A20 & $57(53-62)$ & $53(57-60)$ & $59(53-60.5)$ & 0.413 \\
\hline CFT & $88(78-127)$ & $81.5(102.5-128)$ & $113(82-130.5)$ & 0.232 \\
\hline MCF & $59(54-62)$ & $54(57.5-61)$ & $59.5(53.5-61.5)$ & 0.408 \\
\hline$\alpha$-angle & $72(65-74)$ & $65(70-74)$ & $68.5(66-73)$ & 0.321 \\
\hline LI30 & $100(99-100)$ & $99(100-100)$ & $100(99.5-100)$ & 0.945 \\
\hline LI60 & $93(91-95)$ & $90(93-94)$ & $92(91-94.5)$ & 0.389 \\
\hline MCE & $145(120-162)$ & $118(135-154)$ & $147(115.5-161)$ & 0.377
\end{tabular}

Abbreviations: CT, clotting time (seconds); CFT, clot formation time (seconds); A5, A10, A20, clot amplitude at 5 , 10 and $20 \mathrm{~min},(\mathrm{~mm})$; MCF, maximal clot firmness (mm); LI30, LI60, lysis index at 30 and $60 \mathrm{~min}(\%)$; $\alpha$-angle, alpha angle $\left({ }^{\circ}\right)$; MCE, maximum clot elasticity; NATEM, non-activated rotational thromboelastometry; VD, vaginal delivery; CS, cesarean section; FD, forceps delivery; N: Number of cases, Q1: first quartile, Q3: third quartile.

Blood group $(\mathrm{ABO})$ had no influence on the NATEM parameters except for a minor impact on the LI60 for all comparisons $(p=0.046)$ (Table 5). Rhesus blood group had no impact on any NATEM parameter $(p>0.05)$.

Table 5. NATEM parameters and blood group of neonates.

\begin{tabular}{cccccc}
\hline Parameter & $\begin{array}{c}\text { A }(n=62) \\
\text { Median } \\
\text { (Q1-Q3) }\end{array}$ & $\begin{array}{c}\text { B }(n=35) \\
\text { Median } \\
(\mathbf{Q 1 - Q 3 )}\end{array}$ & $\begin{array}{c}\text { AB }(n=8) \\
\text { Median } \\
\mathbf{( Q 1 - Q 3 )}\end{array}$ & $\begin{array}{c}\text { O }(n=78) \\
\text { Median } \\
\text { (Q1-Q3) }\end{array}$ & $p$-Value \\
\hline CT & $299.5(246-377)$ & $342(255-415)$ & $375(303.5-420)$ & $322.5(250-385)$ & 0.472 \\
\hline A5 & $41(37-47)$ & $39(34-44)$ & $43(35-45.5)$ & $42(37-45)$ & 0.306 \\
\hline A10 & $51(48-57)$ & $49(45-53)$ & $53.5(46-54.5)$ & $52(47-54)$ & 0.294 \\
\hline A20 & $58(54-62)$ & $55(51-60)$ & $59.5(53-61)$ & $57(54-60)$ & 0.169 \\
\hline CFT & $92(77-123)$ & $109(82-138)$ & $102(83-128.5)$ & $97(82-121)$ & 0.284 \\
\hline MCF & $59(55-62)$ & $56(52-61)$ & $59.5(53.5-62.5)$ & $58(54-60)$ & 0.194 \\
\hline$\alpha$-angle & $71.5(66-74)$ & $68(63-74)$ & $70(65-73)$ & $71(67-74)$ & 0.289 \\
\hline LI30 & $100(100-100)$ & $100(99-100)$ & $100(99-100)$ & $100(99-100)$ & 0.394 \\
\hline LI60 & $93(91-95)$ & $93(90-94)$ & $90(90-92)$ & $92(90-94)$ & 0.046 \\
\hline MCE & $146(121-166)$ & $128(109-157)$ & $145(113-162)$ & $136.5(120-153)$ & 0.211
\end{tabular}

Abbreviations: CT, clotting time (seconds); CFT, clot formation time (seconds); A5, A10, A20, clot amplitude at 5, 10 and $20 \mathrm{~min},(\mathrm{~mm})$; MCF, maximal clot firmness (mm); LI30, LI60, lysis index at 30 and $60 \mathrm{~min}(\%) ; \alpha$-angle, alpha angle $\left({ }^{\circ}\right)$; MCE, maximum clot elasticity; NATEM, non-activated rotational thromboelastometry; N: Number of cases, Q1: first quartile, Q3: third quartile.

Regarding maternal coagulation disorders, neonates of mothers with thrombophilia appeared to have a more stable clot in $30 \mathrm{~min}$, LI 30, $(p<0.05)$, although the difference seems to compensate in $60 \mathrm{~min}$. Maternal anticoagulation treatment had no impact on NATEM parameters of neonates. 


\section{Discussion}

In this study we establish reference ranges for ROTEM variables of NATEM assay in cord blood samples of healthy term neonates. To our knowledge, we are the first to determine reference ranges for NATEM assay in cord blood.

ROTEM has recently gained acceptance as a point of care coagulation testing especially in perioperative assessment and blood transfusion guidance, as they provide a more thorough estimation of hemostatic cascade than standard coagulation tests do [4]. One of the most appealing characteristics of the method is real-time, rapid evaluation of the clot formation and degradation that requires a small quantity of blood [11,12]. Consequently, it constitutes a useful tool for diagnosis and treatment of coagulation derangement for all age groups, including the neonatal population [13-24]. However, the usefulness of ROTEM in neonates is not widespread, due to lack of reference ranges and standardization of the values, making the results difficult to interpret as they are usually compared with adults'. This comparison is though misleading owing to age-related differences in coagulation cascade i.e., developmental hemostasis [2,3]. Besides, the neonates cannot be considered "small adults", taking in consideration the differentiation in the hemostatic system.

The most commonly used ROTEM assays in patients with coagulation disorders are EXTEM/INTEM. They require the use of a reagent (recombinant tissue factor and polybrene/ellagic acid respectively) in addition to calcium; as such the results could be influenced and not precisely reflect the hemostatic status of the patient. There are studies, including patients, where EXTEM/INTEM parameters were within normal range although patients were bleeding actively [25]. On the other hand the NATEM assay is only activated by calcium without a supplemental reagent (star-tem ${ }^{\circledR}$ reagent). In this way, it could reveal hemorrhagic disorders more efficiently. It seems to be sensitive at detecting alteration in hemostatic profile of patients with sepsis, infection, trauma-induced coagulopathy (TIC), disseminated intravascular coagulopathy (DIC) and cirrhosis as it reflects the alteration in coagulation only affected by endogenous activator secreted by monocytes [26].

As far as we know the majority of the studies examining ROTEM in neonates have focused on other assays such as EXTEM, INTEM, FIBTEM, etc, except Sidlik et al. [27] who performed modified NATEM analysis with "an increasing concentration of tissue plasminogen activator (tPA)", using though a smaller sample of 101 neonates. Comparing them to adult samples he reported an accelerated clot formation and fibrinolysis. No correlation was noted between modified NATEM parameters and gender, BW, Apgar score, delivery mode, maternal health conditions or medication.

Oswald et al. [13] published age-related reference ranges for EXTEM, FIBTEM and INTEM. This study included distinct pediatric groups, showing an accelerated clot initiation and firmness in the neonatal subgroup. Theodaraki et al. [28] used the same assays including a bigger sample of 215 neonates, establishing reference ranges for that population. Sokou et al. [24] established reference ranges for term and preterm neonates with the use of EXTEM assay. Regarding reference ranges for TEG method, Liu et al. [23] had recruited the largest sample so far of 371 healthy full-term neonates.

In our study, NATEM parameters were influenced by gender. Males presented with a hypocoagulable profile in comparison to females, and had prolonged CT and lower A20, MCF and MCE, with all these values being statistically significant. Theodoraki et al. [28] found lower INTEM LI45 and LI60 values in males, showing an accelerated fibrinolysis, while those values were not gender-related in our findings. Data about sexrelated differences regarding coagulation in neonates are insufficient. In accordance to our findings, Scarpelini et al. [29] and Ahammad et al. [30] noticed a hypercoagulable profile in female adults. The same correlation is also noticed in conventional coagulation tests, described by Sivrikaya et al. [31], with males having prolonged PT and INR. The aforementioned results could be explained by the known fact that females present with a higher level of coagulation factors.

Although only full-term neonates were enrolled, a positive but weak correlation was established between GA and LI30, LI60. Theodoraki et al. [28] reported similar outcomes 
in INTEM and EXTEM assay. Regarding birthweight, no difference was noted in accordance to Sidlik et al. [27]. Mode of delivery did not influence our results in agreement with Schott et al. [32]. On the contrary, Liu et al. [23] observed a prolonged time of clot formation in neonates delivered by CS. In line with Theodoraki et al. [28], no correlation was found in $\mathrm{ABO}$ or Rhesus blood group and NATEM components, except a marginally statistically significant lower value of LI60 in AB blood group. Neonates born to mothers with thrombophilic disorders were noted to have a more stable clot at $30 \mathrm{~min}$, although that was compensated in $60 \mathrm{~min}$, with both groups having the same amount of clot lysis in percentage. Maternal anticoagulation treatment had no impact on our values according to the findings of Strauss et al. [17].

Nonetheless our study has limitations. First of all, since healthy term neonates without need of resuscitation consisted the subject of our study, delayed cord clamping or umbilical cord milking was a common practice. As a result, only small amounts of umbilical blood could be drawn and thus additional tests could not be performed, i.e., complete blood count, PT, aPTT that could be correlated with NATEM parameters. On the other hand, our large sample population $(n=189)$ allows confidence of the results at a level of $99 \%$. In addition to this, it should be mentioned that the study was performed with blood samples from umbilical cord. According to current knowledge, cord blood seems equivalent to neonatal blood and could be used as an alternative, especially in preterm neonates in special clinical conditions such as sepsis evaluation [33-35]. However, especially when it comes to transfusion-guided therapy, data from umbilical cord samples should be interpreted with caution. Larger cohort studies are needed to verify our results and associate them with bleeding or thrombotic complications in ill or preterm neonates.

\section{Conclusions}

Our study has the largest sample size so far regarding cord blood NATEM values in healthy full-term neonates. We established reference ranges in NATEM assay that could be used as a reference group for future studies of neonates with an underlying pathology. Further studies could evaluate NATEM assay as a diagnostic and prognostic tool in neonatal coagulation disorders in order to provide optimal management.

Author Contributions: Conceptualization, R.S.; methodology, R.S., A.S., M.T., E.K.; formal analysis, A.P.; data curation, R.S., A.S., M.T., E.K.; writing—original draft preparation, A.S., M.T., E.K.; writingreview and editing, R.S., Z.I., T.B., S.V., N.I., M.P. All authors have read and agreed to the published version of the manuscript.

Funding: This research received no external funding.

Institutional Review Board Statement: The study was conducted in accordance with the Declaration of Helsinki, and approved by the Institutional Review Board of Aretaieio Hospital, National and Kapodistrian University of Athens (protocol code 310, date of approval 26 March 2021).

Informed Consent Statement: Informed parental consent was obtained from all subjects involved in the study.

Data Availability Statement: Date are available from the corresponding author upon a reasonable request.

Conflicts of Interest: The authors declare no conflict of interest. 


\section{References}

1. Andrew, M.; Paes, B.; Milner, R.; Johnston, M.; Mitchell, L.; Tollefsen, D.M.; Powers, P. Development of the Human Coagulation System in the Full-Term Infant. Blood 1987, 70, 165-172. [CrossRef]

2. Ignjatovic, V.; Mertyn, E.; Monagle, P. The Coagulation System in Children: Developmental and Pathophysiological Considerations. Semin. Thromb. Hemost. 2011, 37, 723-729. [CrossRef]

3. Saxonhouse, M.A.; Manco-Johnson, M.J. The Evaluation and Management of Neonatal Coagulation Disorders. Semin. Perinatol. 2009, 33, 52-65. [CrossRef] [PubMed]

4. Tripodi, A.; Chantarangkul, V.; Mannucci, P.M. Acquired Coagulation Disorders: Revisited Using Global Coagulation/Anticoagulation Testing. Br. J. Haematol. 2009, 147, 77-82. [CrossRef] [PubMed]

5. Motta, M.; Guaragni, B.; Pezzotti, E.; Rodriguez-Perez, C.; Chirico, G. Reference Intervals of Citrated-Native Whole Blood Thromboelastography in Premature Neonates. Early Hum. Dev. 2017, 115, 60-63. [CrossRef] [PubMed]

6. Reverdiau-Moalic, P.; Delahousse, B.; Body, G.; Bardos, P.; Leroy, J.; Gruel, Y. Evolution of Blood Coagulation Activators and Inhibitors in the Healthy Human Fetus. Blood 1996, 88, 900-906. [CrossRef]

7. Monagle, P.; Ignjatovic, V.; Savoia, H. Hemostasis in Neonates and Children: Pitfalls and Dilemmas. Blood Rev. 2010, 24, 63-68. [CrossRef]

8. Weinstein, M.J.; Blanchard, R.; Moake, J.L.; Vosburgh, E.; Moise, K. Fetal and Neonatal von Willebrand Factor (VWF) Is Unusually Large and Similar to the VWF in Patients with Thrombotic Thrombocytopenic Purpura. Br. J. Haematol. 1989, 72, 68-72. [CrossRef]

9. Cannata, G.; Mariotti Zani, E.; Argentiero, A.; Caminiti, C.; Perrone, S.; Esposito, S. TEG ${ }^{\circledR}$ and ROTEM ${ }^{\circledR}$ Traces: Clinical Applications of Viscoelastic Coagulation Monitoring in Neonatal Intensive Care Unit. Diagnostics 2021, 11, 1642. [CrossRef]

10. Katsaras, G.N.; Sokou, R.; Tsantes, A.G.; Piovani, D.; Bonovas, S.; Konstantinidi, A.; Ioakeimidis, G.; Parastatidou, S.; Gialamprinou, D.; Makrogianni, A.; et al. The Use of Thromboelastography (TEG) and Rotational Thromboelastometry (ROTEM) in Neonates: A Systematic Review. Eur. J. Pediatr. 2021, 180, 3455-3470. [CrossRef] [PubMed]

11. Mauch, J.; Spielmann, N.; Hartnack, S.; Madjdpour, C.; Kutter, A.P.; Bettschart-Wolfensberger, R.; Weiss, M.; Haas, T. Intrarater and Interrater Variability of Point of Care Coagulation Testing Using the ROTEM Delta. Blood Coagul. Fibrinolysis 2011, 22, 662-666. [CrossRef]

12. Haas, T.; Spielmann, N.; Mauch, J.; Speer, O.; Schmugge, M.; Weiss, M. Reproducibility of Thrombelastometry $\left(\right.$ ROTEM $\left.^{\circledR}\right)$ : Point-of-Care versus Hospital Laboratory Performance. Scand. J. Clin. Lab. Investig. 2012, 72, 313-317. [CrossRef]

13. Oswald, E.; Stalzer, B.; Heitz, E.; Weiss, M.; Schmugge, M.; Strasak, A.; Innerhofer, P.; Haas, T. Thromboelastometry (ROTEM $\left.{ }^{\circledR}\right)$ in Children: Age-Related Reference Ranges and Correlations with Standard Coagulation Tests. Br. J. Anaesth. 2010, 105, 827-835. [CrossRef] [PubMed]

14. Ravn, H.B.; Andreasen, J.B.; Hvas, A.M. Does Whole Blood Coagulation Analysis Reflect Developmental Haemostasis? Blood Coagul. Fibrinolysis 2017, 28, 218-223. [CrossRef] [PubMed]

15. Romlin, B.S.; Wåhlander, H.; Berggren, H.; Synnergren, M.; Baghaei, F.; Nilsson, K.; Jeppsson, A. Intraoperative Thromboelastometry Is Associated with Reduced Transfusion Prevalence in Pediatric Cardiac Surgery. Anesth. Analg. 2011, 112, 30-36. [CrossRef]

16. Romlin, B.S.; Wåhlander, H.; Synnergren, M.; Baghaei, F.; Jeppsson, A. Earlier Detection of Coagulopathy with Thromboelastometry during Pediatric Cardiac Surgery: A Prospective Observational Study. Pediatr. Anesth. 2013, 23, 222-227. [CrossRef]

17. Strauss, T.; Levy-Shraga, Y.; Ravid, B.; Schushan-Eisen, I.; Maayan-Metzger, A.; Kuint, J.; Kenet, G. Clot Formation of Neonates Tested by Thromboelastography Correlates with Gestational Age. Thromb. Haemost. 2010, 103, 344-350. [CrossRef]

18. Phillips, R.C.; Shahi, N.; Leopold, D.; Levek, C.; Shirek, G.; Hilton, S.; Hyslop, R.; Gien, J.; Kinsella, J.P.; Buckvold, S.; et al. Thromboelastography-Guided Management of Coagulopathy in Neonates with Congenital Diaphragmatic Hernia Supported by Extracorporeal Membrane Oxygenation. Pediatr. Surg. Int. 2020, 36, 1027-1033. [CrossRef] [PubMed]

19. Forman, K.R.; Wong, E.; Gallagher, M.; McCarter, R.; Luban, N.L.; Massaro, A.N. Effect of Temperature on Thromboelastography and Implications for Clinical Use in Newborns Undergoing Therapeutic Hypothermia. Pediatr. Res. 2014, 75, 663-669. [CrossRef]

20. Scott, J.P.; Niebler, R.A.; Stuth, E.A.E.; Newman, D.K.; Tweddell, J.S.; Bercovitz, R.S.; Benson, D.W.; Cole, R.; Simpson, P.M.; Yan, K.; et al. Rotational Thromboelastometry Rapidly Predicts Thrombocytopenia and Hypofibrinogenemia during Neonatal Cardiopulmonary Bypass. World J. Pediatr. Congenit. Heart Surg. 2018, 9, 424-433. [CrossRef]

21. Sokou, R.; Piovani, D.; Konstantinidi, A.; Tsantes, A.G.; Parastatidou, S.; Lampridou, M.; Ioakeimidis, G.; Gounaris, A.; Iacovidou, N.; Kriebardis, A.G.; et al. A Risk Score for Predicting the Incidence of Hemorrhage in Critically Ill Neonates: Development and Validation Study. Thromb. Haemost. 2021, 121, 131-139. [CrossRef]

22. Konstantinidi, A.; Sokou, R.; Parastatidou, S.; Lampropoulou, K.; Katsaras, G.; Boutsikou, T.; Gounaris, A.K.; Tsantes, A.E.; Iacovidou, N. Clinical Application of Thromboelastography/Thromboelastometry (TEG/TEM) in the Neonatal Population: A Narrative Review. Semin. Thrombos. Hemostasis 2019, 45, 449-457. [CrossRef]

23. Liu, Q.; Xu, C.; Chen, X.; Wang, J.; Ke, Z.; Hu, H. Establishing a Reference Range for Thromboelastograph Parameters in the Neonatal Period. Int. J. Lab. Hematol. 2019, 41, 530-535. [CrossRef]

24. Sokou, R.; Foudoulaki-Paparizos, L.; Lytras, T.; Konstantinidi, A.; Theodoraki, M.; Lambadaridis, I.; Gounaris, A.; Valsami, S.; Politou, M.; Gialeraki, A.; et al. Reference Ranges of Thromboelastometry in Healthy Full-Term and Pre-Term Neonates. Clin. Chem. Lab. Med. 2017, 28, 1592-1597. [CrossRef] 
25. Durila, M. Nonactivated Thromboelastometry Able to Detect Fibrinolysis in Contrast to Activated Methods (EXTEM, INTEM) in a Bleeding Patient. Blood Coagul. Fibrinolysis 2016, 27, 828-830. [CrossRef] [PubMed]

26. Gonzalez, E.; Moore, E.E.; Moore, H.B. Management of Trauma-Induced Coagulopathy with Thrombelastography. Crit. Care Clin. 2017, 33, 119-134. [CrossRef]

27. Sidlik, R.; Strauss, T.; Morag, I.; Shenkman, B.; Tamarin, I.; Lubetsky, A.; Livnat, T.; Kenet, G. Assessment of Functional Fibrinolysis in Cord Blood Using Modified Thromboelastography: Assessment of Functional Fibrinolysis in Cord Blood. Pediatr. Blood Cancer 2016, 63, 839-843. [CrossRef] [PubMed]

28. Theodoraki, M.; Sokou, R.; Valsami, S.; Iliodromiti, Z.; Pouliakis, A.; Parastatidou, S.; Karavana, G.; Ioakeimidis, G.; Georgiadou, P.; Iacovidou, N.; et al. Reference Values of Thrombolastometry Parameters in Healthy Term Neonates. Children 2020, 7, 259. [CrossRef] [PubMed]

29. Scarpelini, S.; Rhind, S.G.; Nascimento, B.; Tien, H.; Shek, P.N.; Peng, H.T.; Huang, H.; Pinto, R.; Speers, V.; Reis, M.; et al. Normal Range Values for Thromboelastography in Healthy Adult Volunteers. Braz. J. Med. Biol. Res. 2009, 42, 1210-1217. [CrossRef]

30. Ahammad, J.; Kurien, A.; Shastry, S.; Shah, H.H.; Nayak, D.; Kamath, A.; Badagabettu, S. Age- and Gender-related Reference Ranges for Thromboelastography from a Healthy Indian Population. Int. J. Lab. Hematol. 2020, 42, 180-189. [CrossRef]

31. Sivrikaya, A.; Baran, H.; Abusoglu, S.; Öztürk, B.; Vatansev, H.; Unlu, A. Effect of Gender and Age on the Prothrombin Time (PT), Activated Partial Thromboplastin Time (aPTT) Levels and International Normalized Ratio (INR). Int. J. Mevlana Med. Sci. 2013, 1, 27-29.

32. Schott, N.J.; Emery, S.P.; Garbee, C.; Waters, J. Thromboelastography in Term Neonates. J. Matern.-Fetal Neonatal Med. 2018, 31, 2599-2604. [CrossRef]

33. Christensen, R.D.; Baer, V.L.; Lambert, D.K.; Henry, E.; Ilstrup, S.J.; Bennett, S.T. Reference Intervals for Common Coagulation Tests of Preterm Infants (CME): Coagulation Studies of Preterm Neonates. Transfusion 2014, 54, 627-632. [CrossRef] [PubMed]

34. Neary, E.; McCallion, N.; Kevane, B.; Cotter, M.; Egan, K.; Regan, I.; Kirkham, C.; Mooney, C.; Coulter-Smith, S.; Ní Áinle, F. Coagulation Indices in Very Preterm Infants from Cord Blood and Postnatal Samples. J. Thromb. Haemost. 2015, 13, 2021-2030. [CrossRef]

35. Carroll, P.D.; Christensen, R.D. New and Underutilized Uses of Umbilical Cord Blood in Neonatal Care. Matern. Health Neonatol. Perinatol. 2015, 1, 16. [CrossRef] [PubMed] 